\title{
Prevalence of Undiagnosed Diabetes Cases in Bamako and Surroundings, Mali
}

\author{
Mamadou Diarra*, Moussa Sacko, Moumine Diamouténé, \\ Biochemistry Laboratory of the National Institute of Public Health, Bamako, Mali
}

*Corresponding Author: Mamadou Diarra, Biochemistry Laboratory of the National Institute of Public Health, Bamako, Mali

Summary:

Introduction: Because of its costs, diabetes is a real public health problem. Many people with diabetes go unknowingly at risk of complications. This work contributes to establishing the prevalence of undiagnosed cases in Mali. Goal Determine the prevalence of undiagnosed diabetes cases in Bamako and its surroundings

Material and Methods: Data were collected from the presumed healthy general adult population of Bamako and the surrounding area by administration of a questionnaire, followed by blood samples and fasting blood glucose measurements. People with blood sugar above $1.26 \mathrm{~g} / \mathrm{L}$ were called for a confirmatory test in collaboration with a clinician. The data were analyzed using SPSS software.

Results: The survey involved 809 people, $69.1 \%$ of whom were women and $30.9 \%$ were men. The average age is 37 and a half. Women, young people and civil servants were in the majority. Only 1.7\% of the sample was confirmed diabetic.

Conclusion: This study provides a first estimate of the prevalence of undiagnosed diabetes. Early diagnosis helps prevent complications of the disease and reduces financial costs

Keywords: Diabetes, diagnosed, Bamako, Mali

Abbreviations: IFD: International Diabetes Federation, SPSS: Statistical Package for the Social Sciences, BMI: Body Mass Index, WHO: World Health Organization

\section{INTRODUCTION}

Diabetes mellitus is defined by the chronic rise in the concentration of glucose in the blood (hyperglycemia) and groups together, in a true syndrome, several diseases of different pathogenesis (disorder of the secretion and / or the action of insulin ). [1] It remains one of the major public health concerns. The latest estimates from the International Diabetes Federation (IDF) in 2019 indicate that 351.7 million people, or $9.3 \%$ of the working-age population (20 to 64) have diagnosed or undiagnosed diabetes. This number is expected to increase to 417.3 million by 2030 and to 486.1 million by 2045. The largest increase will occur in regions moving from low income to middle income [2 ]. The prevalence of diabetes is 3.8\% in Africa and 1.28\% in Mali [3]. Unfortunately, many people do not know they have it; often the disease is only detected when the first, sometimes irreversible, symptoms appear. Thus according to the International Diabetes Federation (FID) 50.1\% in the world and 57.9\% in Africa of cases of diabetes are not diagnosed [2]. In France, in the national nutrition health study (ENNS) [4], the prevalence of undiagnosed diabetes cases was high. The relative proportion of these unrecognized diabetes cases was estimated at 30\% in 30-54 year olds and $12 \%$ in 55-74 year old [5]. The objective of this study is to assess the prevalence of undiagnosed diabetes cases in Bamako and its surroundings in Mali.

\section{MATERIALS AND METHODS}

Our sample was obtained from an investigation to establish reference values for biochemical parameters. The investigation concerned presumed healthy subjects aged 18 and over residing in the six communes of Bamako and six other neighboring Bamako: Kalaban-coro, Mandé, Kati, Dialakorodji, Sangarébougou and Moribabougou. A presumed healthy subject is one who has no 
known condition (arterial hypertension, diabetes, etc.), who is not taking medication, or who is not in a particular physiological state. Joining the study was voluntary. The data were obtained by administering a questionnaire followed by a measurement of the weight using a personal scale and the height using a measuring rod, then a blood sample on sodium fluoride. and a blood sugar test. This blood glucose measurement was made on plasma using a "KENZA 240 ISE" biochemical machine. Subjects with a blood glucose greater than $1.26 \mathrm{~g} / \mathrm{L}$ were subjected to a second blood glucose measurement. Those with a second blood glucose greater than $1.26 \mathrm{~g} / \mathrm{L}$ were subjected to a clinical examination for confirmation [6]. Data analysis was performed on SPSS 21 analysis software.

\section{RESULTS AND DISCUSSION}

We surveyed 809 people including 559 women (69.10\%) and 250 men (30.90\%. The average age of the people surveyed is 37.51 years; the average height is 1.66 meters; the average mass is $74,13 \mathrm{Kg}$; the average blood sugar is $5.42 \mathrm{mmol} / \mathrm{L}$ and the average hemoglobin level is $4.75 \%$. The relatively high numbers of women and young people could be explained by the composition of the Malian population and the availability of these social strata.

\subsection{Distribution of the Sample by Body Mass Index and by Sex}

The average Body Mass Index (BMI) is $26.82 \mathrm{Kg} / \mathrm{m} 2$. The distribution of the survey population by BMI is shown in Figure 1 The rate of underweight is higher in men $(2.80 \%)$ than in women. $61.20 \%$ of men have a normal weight against $33.10 \%$ for women. $33.30 \%$ of women are overweight against $28.80 \%$ for men. As for the obesity rate, it is four times higher in women $(32.40 \%)$ than in men (7.20\%). These results are in the same direction as those published by WHO in 2021 which according to which $15 \%$ of women were obese in 2016 against $11 \%$ of men; and $40 \%$ of women are overweight against $39 \%$ for men [7].

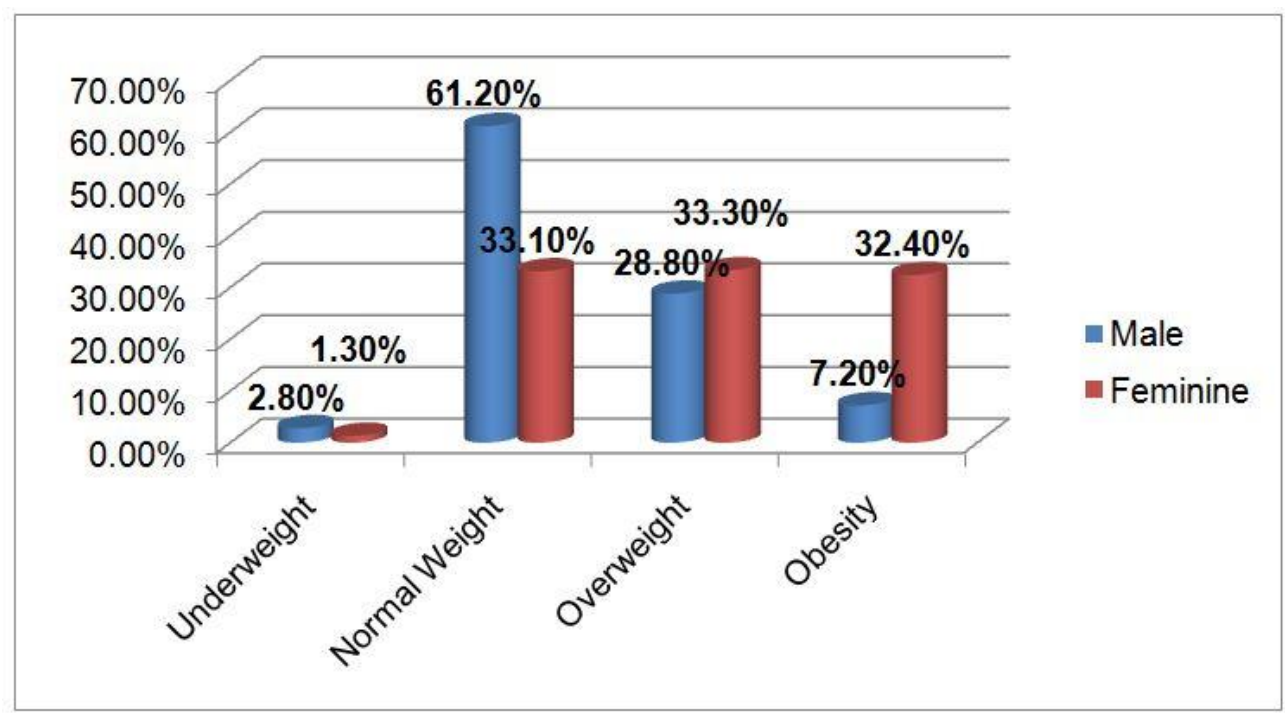

Figure1. Distribution of the sample by Body Mass Index and by sex

\subsection{Distribution of the Sample by Diabetic Status}

Of the 809 people surveyed, 759 or $93.80 \%$ have normal blood sugar levels against 50 or $6.20 \%$. The distribution of people surveyed by diabetic status is shown in Figure 2 On the first visit, we detected 50 cases of hyperglycemia, or $6.2 \%$ of the sample. At the second visit 14 people were confirmed diabetic, ie $1.7 \% .85 .7 \%$ of these new diabetics (unrecognized diabetes) are female. This could be explained by the relative sedentary lifestyle of women compared to men [8]. The majority of these diabetics are administrative workers (57.1\%) compared to $21.4 \%$ artisans and $21.4 \%$ housewives. These results are in line with those of the French Institute for Public Health Surveillance [4]. This could be explained not only by the place of study, but also by the fact that administrative officers put little physical effort into the performance of their duties. 


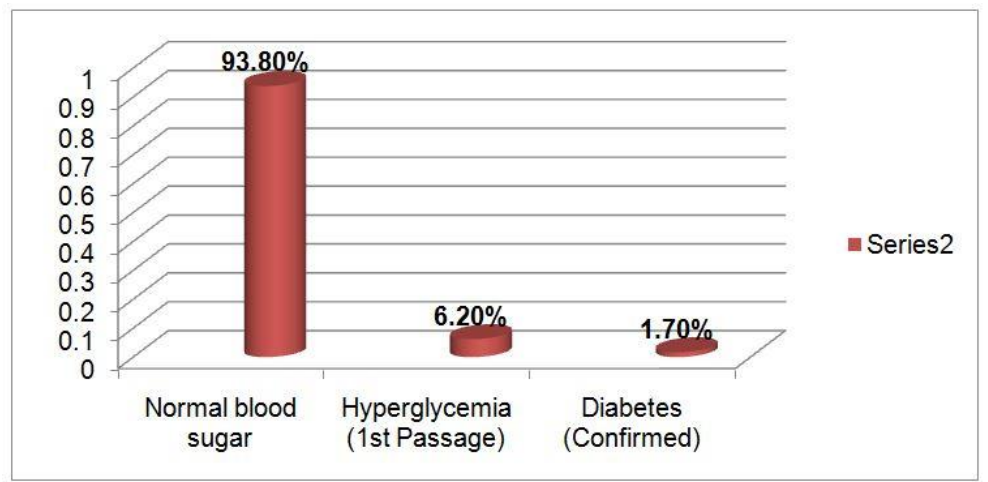

Figure2. Distribution of the sample by diabetic status

\subsection{Distribution of Undiagnosed Diabetes Cases by Age Group}

The average age of these diabetics is 39.79 years. The youngest is a 25 -year-old woman and the oldest a 58-year-old man. The distribution of unrecognized diabetes cases is shown in Figure 3 The majority of unrecognized diabetes cases are found in the 30 - 54 age group with $78.60 \%$ against $7.10 \%$ for the 55 and over age group. These results are in the same direction as those found by Bonaldi $\mathrm{C}$ et al. In France [5]. The 30 to 54 age group includes people in full activity who very often do not do enough health checks, and it is at these ages that type 2 diabetes most commonly appears.

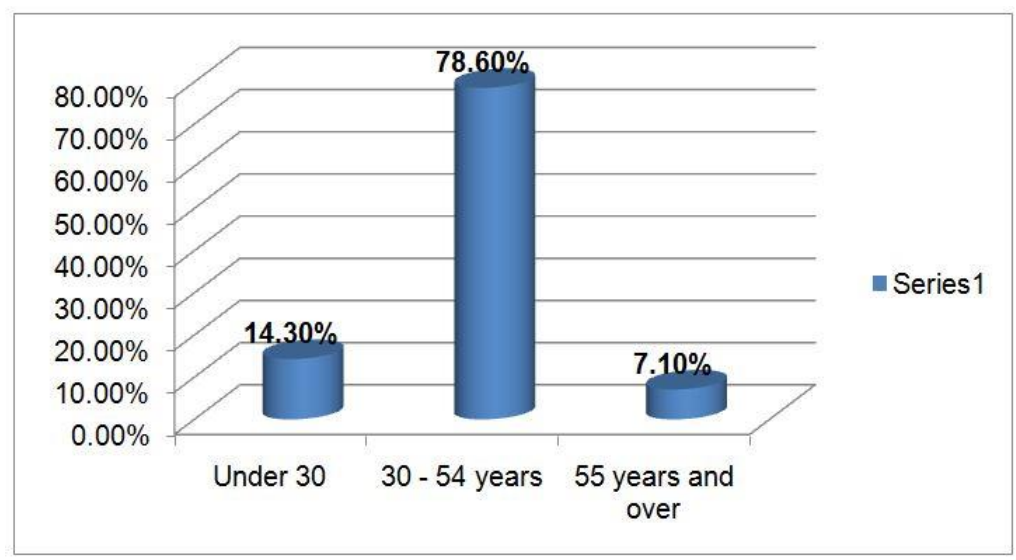

Figure3. Distribution of diabetics by age group

\subsection{Distribution of Diabetics by BMI}

The average Body Mass Index (BMI) of new diabetics is $31.49 \mathrm{Kg} / \mathrm{m} 2$. The small BMI is $23.05 \mathrm{Kg} /$ $\mathrm{m} 2$ and the largest is $41.09 \mathrm{Kg} / \mathrm{m} 2$. The distribution of unrecognized diabetes cases by IMC is shown in Figure 4. Among the unrecognized cases of diabetes, $64.30 \%$ are people with obesity, $21.40 \%$ are overweight and $14.30 \%$ are people of normal weight. These results confirm those found by WANG.Y et al. in 2005 according to which obesity and overweight are real risk factors for type 2 diabetes [9].

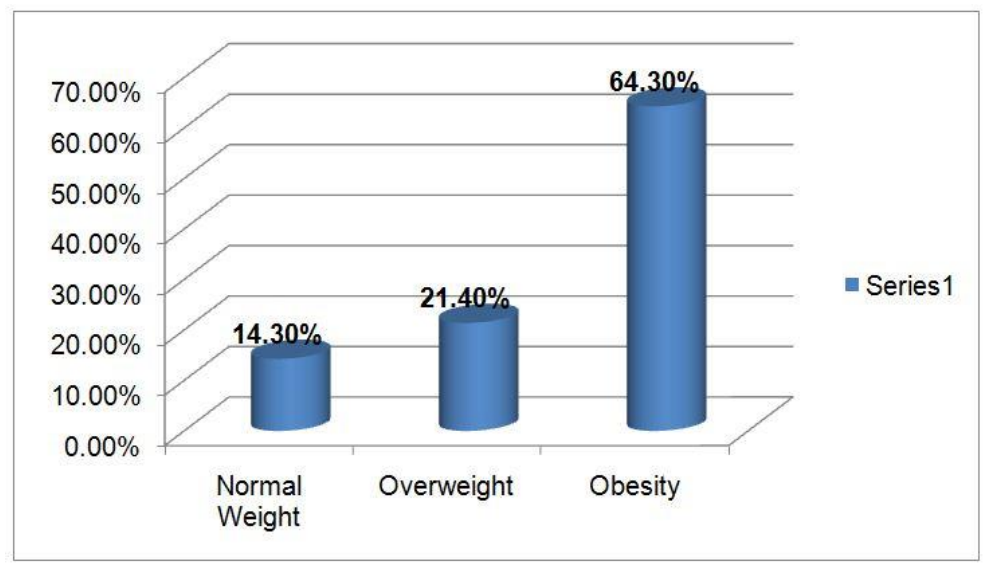

Figure4. Distribution of diabetics by BMI 


\section{CONClusion}

Based on a local sample, this study provides a first estimate of the prevalence of undiagnosed diabetes and moderate fasting hyperglycemia in adults aged 18 and over living in Bamako and its surroundings. She confirms that obesity and overweight are risk factors for developing type 2 diabetes and that their rates are relatively higher in women. Early diagnosis helps prevent complications of the disease and reduces financial costs.

\section{REFERENCES}

[1] Michel Rodier "Definition and classification of diabetes" Nuclear Medicine - Functional and metabolic imaging - $2001-$ vol. $25-\mathrm{n}^{\circ} 2 \mathrm{P} 91$

[2] International Diabetes Federation "IDF Diabetes Atlas" 9th edition, 2019 P 36, 38, 43.

[3] International Diabetes Federation “IDF Diabetes Atlas” 6th edition, 2013 P 34, 120.

[4] Institute for health surveillance. National health nutrition study ENNS, 2006. Nutritional situation in France in 2006 according to objective indicators and benchmarks of the National Health Nutrition Program (PNNS). First results. Saint-Maurice: InVS; 2007.http: //www.invs.sante.fr/publications/2007/nutrition _enns/RAPP_INST_ENNS_Web.pd

[5] Bonaldi C, Vernay M, Roudier C, Salanave B, Oleko A, Malon A, et al. A first national prevalence estimate of diagnosed and undiagnosed diabetes in France in 18- to 74-year-old individuals: the French Nutrition and Health Survey 2006/2007. Diabet Med 2011; 28 (5): 583-9

[6] Michel Rodier. Definition and classification of diabetes, Nuclear Medicine - Functional and metabolic imaging - $2001-$ vol.25 - $\mathrm{n}^{\circ} 2, \mathrm{P} 92$

[7] WHO, Obesity and overweight, 2021

[8] WHO, Global Strategy on Diet, Physical Activity and Health, 2021

[9] WANG Y., RIMM E.B., STAMPFER M.J., WILLETT W.C., HU F.B. Comparison ofabdominal adiposity and overall obesity inpredicting risk of type 2 diabetes amongmen. Am J Clin Nutr 2005; 81: 555-563

Citation: Mamadou Diarra." Prevalence of Undiagnosed Diabetes Cases in Bamako and Surroundings, Mali", International Journal of Clinical Chemistry and Laboratory Medicine (IJCCLM), vol. 7, no.1, pp. 3740, 2021. http://dx.doi.org/10.20431/2455-7153.0701004

Copyright: (C) 2021 Authors. This is an open-access article distributed under the terms of the Creative Commons Attribution License, which permits unrestricted use, distribution, and reproduction in any medium, provided the original author and source are credited. 